\title{
Policy or Window Dressing? Exploring the Impact of Poverty Reduction Strategies on Poverty Rates among the Canadian Provinces
}

\section{Charles Plante}

Ph.D. Candidate, Sociology, McGill University

Ph: +1 3065140890. Email: charles.plante@usask.ca 


\title{
Policy or Window Dressing? Exploring the Impact of Poverty Reduction Strategies on Poverty Rates among the Canadian Provinces
}

\begin{abstract}
$\underline{\text { Abstract }}$
Poverty reduction strategies (PRS) have become a popular instrument for addressing poverty globally. In Canada, all ten provinces have committed to adopting PRS. The province's commonalities and differences provide an ideal testing ground for studying their effects. Do PRS actually reduce poverty? According to their detractors, governments use PRS as 'window dressing' to gloss over unsuccessful poverty reduction efforts. In this study, I identify the timing of the introduction of PRS action plans and explore whether they have coincided with changes in provincial poverty rates. I find that more often than not rates have dropped before rather than after the introduction of PRS. This suggests that governments have indeed used PRS as window dressing, but to showcase and claim credit for poverty reduction successes.
\end{abstract}

Keywords: poverty reduction strategy, social policy, credit claiming, government, Canada, provinces.

\section{Introduction}

Poverty is a multifaceted problem that requires action on many fronts. Over the last two decades, poverty reduction strategies (PRS) have emerged globally as an increasingly popular policy instrument to deal with this complexity (Noël 2006). Initially proposed by the World Bank and International Monetary Fund for developing countries (Levinsohn 2003), rich countries began to implement them beginning with the UK in 1999 (Collin 2007). In the European Union, these plans are known as National Action Plans on Social Inclusion and are widespread (Atkinson et al. 2005).

In Canada, the first PRS was formally committed to in Quebec in its Act to Combat Poverty and Social Exclusion in 2000 and rolled out in 2004. Since then, Canada has seen a proliferation of first provincial PRS, peaking in 2009 and continuing until the last of the ten provinces, British Columbia, made its commitment to introduce a plan in 2017. At the time of this writing, early 2018, three provinces are implementing their second action plans and the original province, Quebec, is implementing its third.

The Canadian provinces provide an ideal testing ground for advancing our understanding the impacts of PRS (Imbeau et al. 2000). On the one hand, the provinces are highly similar having more in common with one another than they do with other jurisdictions (Bernard and Saint-Arnaud 2004). On the other hand, they differ in important ways that can bring the effects 
of policy intervention into relief (for example, van den Berg et al. 2017). Canada also benefits from a highly coordinated systems of data collection and common indicators.

Following a 2014 commitment to develop a PRS, in 2016 Saskatchewan became the seventh of the Canadian provinces and the latest to introduce its first poverty reduction action plan. The plan met with widespread condemnation from the local poverty advocacy community.

Compared to other provincial action plans it was certainly unusual, reading as a laundry list of already existing programs and initiatives and proposing no new ones. Still, in 2016 Saskatchewan had among the lowest poverty rates in the country.

At their best, PRS set targets and timelines and chart a course for poverty reduction within their jurisdictions; they bring together stakeholders from inside and outside of government to coordinate and focus their efforts; and they overcome traditional silos and piecemeal approaches to benefits and service provision to create a united front in the fight to reduce poverty (Notten and Laforest 2016; MacInnes et al. 2014). Repeated PRS can serve as a basis for deliberative evidence-based policy learning.

However, as the community response to Saskatchewan's PRS makes clear, it is far from certain that any given PRS reduces poverty. According to their strongest detractors (for example, Greason 2012), PRS are just another way for governments to say they are doing something about poverty when they are really not. In effect, governments are accused of using PRS as 'window dressing' (Levinsohn 2003:9) to dress up lukewarm poverty reduction efforts and gloss over failures and inaction.

Despite their rapid proliferation, at this time, there is surprisingly little academic research on PRS. In this study, I present a bird's eye view of the impact of provincial PRS in Canada to address the question: what effect, if any, have PRS had on poverty rates? As one of the first studies to examine this question, my aim is not to provide a definitive answer to it, but to use evidence to narrow discussion and unearth interesting hypotheses to advance more in-depth study in the future.

In the spirit of exploration, I eschew more complex forms of statistical analysis, adopting instead a relatively straightforward descriptive empirical strategy which compares poverty levels before and after the introduction of provincial PRS action plans. I then compare these developments to changes in poverty rates going back to 1976 . I operationalize poverty in Canada using forty years

\footnotetext{
1 “" It's a really long document but most of it is listing things that are already being done and there's very little in terms of an actual plan,' [local physician and poverty advocate Ryan Meili] said, 'So to call this a Poverty Reduction Strategy is pretty big stretch"” (CBC News 2016) (see also Fraser 2016).
} 
of Statistics Canada data and the popular Low Income Measure (LIM) (Murphy, Zhang, and Dion 2010).

I find that there has been no definitive relationship between the timing of PRS action plans and changes in poverty rates among the provinces. Looking at five-over-five years changes in poverty over time, action plans in most provinces have actually tended to follow prolonged periods of poverty reduction rather than give rise to them (Ontario is the exception). Moreover, every province has seen more impressive five-over-five years improvements in poverty rates in earlier decades.

These results suggest that governments may be timing the introduction of their first action plans to showcase recent poverty reductions rather than ensure them in the future - a dynamic that political scientists call "credit claiming" (Bonoli 2012; Weaver 1986). I discuss the strengths and limits of this conclusion in the closing sections of this paper and identify promising directions for future study.

\section{Poverty reduction strategies}

In Canada, PRS provide a framework of targets and timelines, oversight, and processes of internal and external review that enable governments and the public to monitor progress toward poverty reduction over the medium and long term (5-10 years) (Notten and Laforest 2016; MacInnes et al. 2014). They also identify the specific institutional arrangements and policies that the province will use to ensure it meets its objectives.

Policies that are identified in PRS generally include a combination of new measures and improvements to existing one. For example, in its 2006 poverty reduction action plan, the Government of Newfoundland and Labrador lists dozens of policies it will maintain, adjust and introduce. Among them, it explains that in order to further incentivise employment it will change the way that it calculates income-adjusted social housing rent rates so that it excludes pension and employment insurance contributions (GoNL 2006:27).

The multitude and minutiae of the kinds of policies that are identified as contributing to PRS makes it useful to consider the impact of the plan overall. In addition, PRS ordinarily entail a number of higher level guidelines regarding how action around poverty alleviation should be coordinated, which are expect to have impacts on poverty rates over and above specific measures.

For example, Notten and Laforest (2016) argue that PRS in Canada have adopted an innovative approach to policy making and implementation that combines collaborative governance and performance management practices. Solving poverty demands action and feedback not just from 
government actors and service providers, but also non-governmental agencies, advocates, the public and large, and the "first voice" experience of the poor themselves (Holden and Muhajarine 2015). Collaborative governance entails moving away from top down decision-making to processes that involve a wide range of stakeholders while performance management practices provide a set of tools to focus, coordinate and assess the actions of so many agents.

Over the long term, repeated PRS promise to provide a foundation for the kind of evidence-based deliberative policy learning which Sanderson (2009) calls "intelligent policy making." Adopting this approach, policy efforts are hypotheses to be tested in practice and improved upon. Repeated PRS set out poverty reduction objectives, track and assess progress, and make adjustments as needed with each iteration. ${ }^{2}$

In Canada, there have been as many approaches taken to provincial PRS as there have been adopting provincial governments. Notten and Laforest (2016), for example, compare and contrast the cases of Newfoundland and Labrador, Quebec, Ontario and Manitoba in terms of three dimensions: institutional arrangements, stakeholder involvement, and strategic management and measurement. They find that no two of the four provinces have adopted the same arrangements in any one of these dimensions.

However, notwithstanding differences of approach and implementation, at least one common theme unites the PRS of all adopting Canadian provinces: their focal aim is to reduce poverty.

\section{The poverty reduction strategy process}

In this paper I assess the impact PRS have had on overall provincial poverty rates. In order to do this effectively, it is important to accurately identify when we should expect them to impact poverty levels. PRS typically unfold as a series of events beginning with a commitment, followed by some amount of consultation, the adoption of an action plan and then several years of implementation, and, finally, an assessment and review (see also Notten and Laforest 2016). In several provinces this process has been punctuated by the adoption of related legislation.

Initial commitments by themselves are not expected to impact poverty rates. Nonetheless, it is important to distinguish them because provinces are often given credit for meeting this relatively low hurdle. Commitments are official statements of intent by governments that they will deliver a poverty reduction action plan. For example, several provinces indicated their intent to deliver PRS in Speeches from the Throne. ${ }^{3}$

\footnotetext{
${ }^{2}$ In the EU, this dynamic is also meant to play out cross-sectionally among countries via the "open method of coordination" (Ferrera, Matsaganis, and Sacchi 2002).

${ }^{3}$ In Canada, a Speech from the Throne is an event used to open a parliamentary legislative session. A prepared speech is given in the legislature by a representative of the reigning monarch — at the provincial level, this is the
} 
The provinces vary greatly in how initial commitments fit into their PRS process and the time it takes them to follow through with action plans. At one extreme, Ontario and Manitoba's official commitments actually coincided with the introduction of their action plans. Most provinces, however, deliver their action plans a year or more later. At the other extreme, Alberta committed to enacting a PRS in 2012 but has yet to deliver on it promise at the time of this writing, six years on.

Insofar as PRS are successful in the short to medium term, we should expect to see their impact coinciding with and following the delivery of action plans. Action plans state the aims of the PRS and detail what courses of action the province will take in order to meet them. Promised actions tend to include a mixture of administrative measures, adjustments to existing social programs and services, and commitments to introduce new benefits and/or services.

The timing of action plans is relatively easy to pin down as they are delivered in the form of widely distributed public documents. Figure 1 provides a visual summary of the timing of key PRS events in each province overlayed with the political affiliation of sitting provincial governments. The action plans are also listed and linked to in the appendix to this article.

[***FIGURE 1 HERE****]

Over time the PRS process can become cyclical (Notten and Laforest 2016). Once initial action plans have been implemented and assessed, governments will often initiate new rounds of consultation and introduce new action plans. At the time of this writing, Quebec is in the process of implementing its third action plan, meanwhile, New Brunswick, Manitoba and Ontario are well into their second.

However, there is considerable variation in the pace of this cyclical dynamic and it is not guaranteed. Newfoundland and Labrador, the second province to adopt its first plan has yet to adopt its second after more than a decade. In contrast, Manitoba's second plan followed its first after only three years.

Quebec, Ontario and Manitoba have introduced legislation that stipulates the timing of ongoing PRS events and ensures that the cycle is repeated at regular intervals. Insofar as an ultimate aim of PRS is long term deliberative policy development then legislation may yet have historic impacts. However, we would not expect it to have short to medium term impacts independent of action plans.

lieutenant governor-which lays out the government's agenda and focus for the coming sitting. It is common to make important policy announcements in these speeches. 


\section{Action plans and poverty rates}

If PRS are enacting initiatives and policies that are reducing poverty then this impact, at least in the short to medium term, will be associated with their action plans. Given that poverty has not been eliminated in any province, we should expect poverty levels to drop and/or decline around their introduction. This effect should be particularly pronounced about initial action plans, but may also follow subsequent plans.

However, if PRS tend to be used by governments merely to dress up their efforts - the "window dressing hypothesis" - or claim credit, we should find no relationship between the timing of action plans and changes in poverty rates.

\section{Operationalizing provincial poverty}

\section{Data}

Statistics Canada releases low income estimates calculated using different thresholds that are widely used to track poverty in Canada (Hunter and Miazdyck 2006). This data is distributed in CANSIM tables 206-0041 and 206-0042 and is freely available online. However, as aggregate estimates, the kinds of statistical analysis that we can do with them is limited. For this reason, I accessed the raw micro data through the Canadian Research Data Centres Network.

Over the past four decades, Canada has collected income data using three surveys: the Survey of Consumer Finances from 1976 to 1997, the Survey of Longitudinal Income Dynamics (SLID) from 1992 to 2011, and the Canadian Income Survey (CIS) from 2012 to the present day. Statistics Canada has done considerable work to correct for differences between the surveys that might bias comparisons (Statistics Canada 2015).

These datasets contain 1,088,874 observations of individual persons spanning forty years of observation, between 1976 and 2015. However, they are not without their limitations. The surveys are administered by telephone and are thus unlikely to capture homeless populations. In addition, their sampling frame excludes residents of institutions and people living on reserve. Statistics Canada notes that these exclusions represent less than $3 \%$ of the Canadian population.

The exclusion of people living on reserve makes it problematic to compare poverty levels between the three Prairie Provinces (Alberta, Manitoba and Saskatchewan), where these populations represent a relatively large share of the population, and the other provinces. Fortunately, the focus of this study is comparisons within provinces, rather than among them. Additionally, on reserve populations fall under federal jurisdiction and are not targeted by provincial poverty reduction efforts. 


\section{Poverty status}

Statistics Canada formulates three sets of low income estimates based on different thresholds: the Low Income Measure (LIM); the Market Basket Measure (MBM); and the Low-Income Cut-Off (LICO). In this study, I adopt as my measure of poverty the LIM. I do so primarily for two reasons: first, the LIM is the most widely used measure of poverty globally (Murphy et al. 2010); second, the purpose of this paper is to provide a preliminary survey of the impact of provincial PRS in Canada and the LIM is sufficient to this end.

The LIM is defined simply as fifty percent of median household adjusted disposable income. Adjusted disposable income is defined as income net of taxes and transfers and adjusted for the size of the household. Larger households benefit from economies of scale which results in each additional member costing fewer additional dollars to support. It is common practice to adjust for this by dividing disposable income by the square root of household size (Murphy et al. 2010).

The LIM is the most widely used measure of poverty globally, mainly because it is easy to calculate in a reliable fashion across diverse populations (Brady 2003). All that is needed to calculate it is information on the distribution of household disposable income and their size. In contrast, the LICO and MBM, both depend on information on the price of goods and consumer spending habits that are unique to Canada (in fact, this information is sufficiently fluid that it also makes comparisons within Canada over time difficult).

The primary criticism of the LIM is that its median is based at the national level. Theoretically, the LIM is meant to capture the same standard of deprivation among diverse contexts (Brady 2003). Basing the LIM at the national level assumes that the same amount of resources is able to achieve the same quality of life throughout the country. This assumption has been questioned by researchers in Quebec where prices and wages tend to be lower (see, for example, CEPE 2009).

Nonetheless, the aim of this study is not to make poverty comparisons among the provinces. It is instead to trace whether poverty levels are affected about the timing of PRS action plans within provinces. As long as the impacts of provincial poverty reduction efforts are distributed widely among the least well of fifth or so of households, adopting either measure will motivate similar findings. Relatedly, this will also be the case using LIM calculated based on different cut-offs, such as forty or sixty percent of median income.

\section{Poverty rate}

The provincial poverty rate is defined as the proportion of the population whose household adjusted disposable income falls below the LIM. There are well established limitations in using such a simple measure of aggregate poverty to assess poverty reduction efforts (Brady 2003; Osberg and $\mathrm{Xu} 2008$ ). Specifically, it is insensitive to the effects of policy efforts that improve 
people's well-being but do not raise raise their incomes above the LIM. Meanwhile, it is overly sensitive to small changes in income near the threshold. A cynical government could, for example, game the poverty rate by issuing transfers to the least poor among the poor.

However, because the aim of this study is only to provide preliminary examination of the impact of provincial poverty reduction efforts I have decided to opt for this simpler and widely recognized measure. Measures like the Sen-Shorrocks-Thon measure of poverty intensity (Osberg and Xu 2000) and advanced moments of the Foster-Greer-Thorbecke measure (Foster, Greer, and Thorbecke 1984) provide a more complete picture of poverty, but most decision makers and citizens continue to think in terms of poverty rates.

\section{$\underline{\text { Analysis }}$}

If PRS have had an impact on poverty levels, we would expect them to be different and lower following the enactment of PRS action plans. Figure 2 illustrates the three kinds of trajectories in poverty rates we should see if PRS are successful.

\section{[***FIGURE 2 HERE****]}

First, PRS can have an immediate effect on poverty which reduces poverty immediately after a plan is implemented and no further effect afterward. This is illustrated in the second panel of Figure 2 . This produces a discontinuity about the year the action plan is introduced, but does not affect the slope of the trend.

We might expect this kind of impact when action plans enact policies that have an immediate effect on poverty rates. For example, an increase in social assistance rates which shifts household incomes above the poverty line or workfare initiatives which immediately put people to work and increase their earned income in the short term.

Second, PRS can have an incremental and continuous impact, so that each year they reduce poverty by some additional amount. This kind of effect does not result in a discontinuity about the year the PRS was enacted but it does reduce the slope of the poverty trend. We would expect this kind of pattern if poverty reduction efforts take time to lift people out of poverty and induce positive cumulative effects. It is illustrated in the third panel of Figure 2.

If immediate increases to social assistance improve people's capacity to balance work and family so that they can excel at both, and/or make investments in themselves that can lead them to pursue more favourable labour market outcomes, we would expect it to have a cumulative effect on poverty reduction over time. The effects of government initiatives can also take time to have 
effect, either because it takes time for them to reap benefits, such as in the case of investment in upskilling, or because it can take governments time to enact programs.

Finally, a successful PRS can have some combination of both and immediate and ongoing impact on poverty levels as illustrated in the fourth panel in Figure 2.

\section{Descriptive estimates}

In this preliminary study of the relationship between PRS events and poverty rates I adopt a straightforward descriptive strategy. I am ultimately interested in answering the question, do poverty levels tend to be lower after PRS have been enacted than before? If PRS are merely being used by governments to dress up their efforts on policy but not have tangible effects, we would expect there to be little relationship between the timing of PRS events and changes in poverty trends and levels.

Because poverty action plans most commonly apply to roughly five year intervals, I focus on making comparisons between the five years leading up to action plans and the five years following, including the year in which plans were enacted. Making comparisons between shorter intervals risks missing the impact of initiatives that take time to implement and/or have have effects. Making comparisons between longer intervals risks diluting the impact of a given governmental and policy regime.

In order to situate these developments in historical context, I calculate ten year overall poverty rates in each of the ten provinces and in the country as a whole between 1976 and 2015. I also calculate five-over-five year changes in poverty for the same interval.

Poverty rates are statistical estimates of the proportion of people in a population that are poor. As such, they are measured with error. For this reason, it was important to return to the raw Statistics Canada data to calculate standard errors for these descriptive statistics. Since the descriptives I work with are calculated over pooled years, samples were very large and errors quite small.

\section{$\underline{\text { Results }}$}

\section{Historic trends in poverty}

Most provinces have seen a decrease in poverty since the 1970s, especially those in the Maritimes. Between 1976 and 1985, Newfoundland and Labrador, PEI and New Brunswick exhibited poverty rates that were near or in excess of $20 \%$. Although, Newfoundland and Labrador maintained an average poverty rate in this range much longer, even as late as between 1996 and 2005, by the 2006 to 2015 period, all had rates below $16 \%$. 
Even though several provinces saw large declines in poverty between the late 1970s and the present, two of Canada's most affluent provinces saw substantial increases in poverty which have offset gains at the national level. In Canada as a whole, the average rate was $12.7 \%$ between 1976 and 1985 and increased to $13.5 \%$ between 2006 and 2015. This is in large part because of a 3.4 percentage point increase in Ontario over this period, from $10.2 \%$ to $13.6 \%$, and 3.2 percentage point increase in British Columbia, from 11.4 to 14.6.

Among those provinces that were least poor between 1976 and 1985, only Alberta has seen their average ten-year poverty levels consistently decline. From $10.6 \%$ in the earliest period observed, to $8 \%$ in the most recent period, a modest but significant decline of 1.4 percentage points.

[***TABLE 1 HERE****]

\section{Immediate effects of poverty reduction strategies}

Figure 3 illustrates poverty trends in the five years preceding the adoption of province's first PRS and the five years following, including the year in which they were enacted. In order to more clearly illustrate the trend in poverty levels before and after action plans, OLS regression lines are fitted for each interval. The last panel superimposes all the trends onto one. Evidently, there has been no single pattern in poverty rates around the introduction of provincial PRS.

Only Newfoundland and Labrador has exhibited the pattern depicted in Panel 2 of Figure 2 wherein the introduction of a PRS has an immediate impact on poverty levels. Note that even though poverty levels continued to decline after the introduction of the plan, the slope remained the same, suggesting that the plan may not have had an ongoing impact on poverty levels. In Nova Scotia and Manitoba, plans did not have an immediate effect on overall poverty levels, but they do appear to have had an ongoing incremental impact in the years that followed.

Conversely, we observe trends at odds with what we would expect to be the impact of successful PRS in the other provinces. Poverty rates that were steadily declining in Manitoba leveled out in the years following their first action plan and in Quebec a downward poverty trend turns upward at the time that its first action plan was introduced. Meanwhile, increasing poverty levels in Ontario and PEI continued to increase after their action plans were implemented, with latter's actually appearing to accelerate.

\section{[***FIGURE 3 HERE****]}

These results are further evidenced in Table 2 which present average poverty rates for the five years before and after actions plans and their differences for all the provinces that have enacted 
them. Whereas, negative changes following first action plans are substantial and statistically significant in Newfoundland and Labrador and Nova Scotia, they are positive and statistically significant in Ontario and PEI.

\section{[***TABLE 2 HERE****]}

All three provinces that have enacted second action plans have seen poverty levels that are slightly higher afterward, although this difference is only statistically significant in Ontario and Manitoba. It should be noted that since Ontario and Manitoba enacted their second action plans after 2011 (2014 and 2012, respectively) estimates for these provinces are censored and may change as data for later years become available.

Meanwhile, the cases of Manitoba, Nova Scotia, New Brunswick and Quebec suggest that we should not stop at just five-over-five year before and after action plans comparisons. In Manitoba and Nova Scotia, poverty rates increased in the years leading to their first action plan and declined afterward. Comparing the averages between these periods results in these trends cancelling each other out, even though the latter is evidence of success.

In Quebec and New Brunswick, poverty levels declined before they leveled out or increased. As a result, average levels tended to be lower after the action plan, even though in their cases poverty reductions had stalled after plans were enacted.

\section{Effects in historical context}

In order to overcome some of the limitations inherent in comparing five-over-five year intervals before and after action plans, Figure 4 I illustrates all five-over-five year changes in the national and provincial poverty rates in Canada between 1981 and 2011. No change is indicated in this Figure by a solid line in each panel. When the five-over-five year markers are above the solid line, poverty levels have increased; and, when they lay below the line, poverty levels have decreased.

\section{[***FIGURE 4 HERE****]}

Broadly speaking, changes in poverty rates, both positive and negative, have been the historical norm in Canada's provinces. The province with the steadiest five-over-five year changes has been Alberta although even it regularly experiences fluctuations in excess of 1 percentage point. At the other extreme, PEI saw fluctuations of nearly 5 percentage points in the 1990s. On average, all the provinces have seen periods in which poverty levels tended to increase, and others in which they tended to decline. 
The enactment of provincial action plans are indicated in Figure 4 by white circles. In not a single province is the five-over-five year change in poverty levels about the PRS the largest decrease in poverty levels seen over the thirty year period of observation. Even Newfoundland and Labrador's substantial five-over-five year change of -4.2 percentage points in 2006 is not as great as the five-over-five year change it experienced in 1988 of -5.28 percentage points.

In the context of historical fluctuations in poverty levels, the timing of most action plans is also notable. The first action plans in Newfoundland and Labrador, Nova Scotia, New Brunswick and Quebec all occurred after prolonged periods of five-over-five year decreases in poverty rates, when these changes were the most promising they had been in more than a decade. The timing of Manitoba's action plan follows a similar though more muted downward historical trend in changes. ${ }^{4}$

Although the introduction of Saskatchewan's action plan happened too recently to be shown in Figure 4, it too has been introduced following prolonged periods of declining poverty rates. Meanwhile, though yet to enact an action plan, Alberta's poverty levels have been declining steadily since the mid-1990s.

The only province to enact a PRS when changes tended to previously be on the rise is Ontario in 2008. Quebec's second action plan also followed a recent uptick in five-over-five year changes in poverty levels.

The last panel in Figure 4 superimposes all of the information of the previous panels onto one. It shows that in addition to provincial trends in changes in poverty rates there have also been nation level trends. Levels were more likely to decline in the country as a whole in the 1980s and early 1990s and increase in the late 1990s. In the 2000s, poverty levels were again more likely to decline.

\section{Discussion}

\section{Policy or window dressing?}

Have PRS tended to reduce poverty in Canada's provinces or does the evidence suggest they were simply used by governments as window dressing to bolster public perceptions of their record? At best, some provinces did indeed reduce poverty in the years after their plans were enacted — specifically, Newfoundland and Labrador, Nova Scotia, and Manitoba — but many others did not.

\footnotetext{
${ }^{4}$ Five-over-five years changes will be affected by levels after the introduction of an action plan in the four years leading up to it. Note that this and the next paragraph speak to longer run trends in these changes.
} 
Porincial poverty trends lend considerably more support to the window dressing hypothesis. That being said, they also support a somewhat less cynical interpretation than has been levied against PRS by their greatest detractors. Even though there appears to be no tendency for poverty rates to fall after the introduction of PRS action plans, there does appear to be a tendency for poverty to fall before them. This suggests governments may be enacting plans to dress up their efforts by claiming credit for achievements rather than by glossing over failures.

In the political science literature, the seminal exposition of credit claiming is Weaver's 1986 treatment of it in the wider context of blame avoidance. He argues that, as a result of the public's aversion to losses, politicians are likely to pursue a strategy of blame avoidance over credit claiming and shirk the discretion which is offered by initiatives like PRS.

However, Weaver also notes that credit claiming is likely when the perceived costs of a policy is relatively low and its benefits great. Bonoli (2012) observes that modern states are presented with opportunities for "affordable credit claiming" when policies can be seen as "win-win" (104) such as in the case of pro-employment interventions that reduce dependency and increase the tax base. Interestingly, MacInnes et al. (2014) observe that these kinds of policies occupy a central role in PRS.

The use of credit claiming to dress up policy efforts appears to be particularly prevalent as far as first action plans are concerned. At the time of this writing, there is too little information on poverty levels around second action plans to say anything conclusive about them, but their use as window dressing could be mitigated by the kinds of legislative and institutional restrictions initial commitments and action plans put in place.

Rather than thinking of PRS as a catalyst for reducing poverty in Canada's provinces, it may be more accurate to think of them as a symptom of successful poverty reduction efforts more generally. In the most favourable light possible, first PRS could be regarded as an intermediate poverty reduction phase wherein governments that have successfully reduced poverty in the recent past look for ways to go even further.

As poverty levels fall, efforts may need to become increasingly targeted and coordinated in order to make further gains. Action plans tend to include multiple and prominent references to how governments will improve monitoring and coordination (Notten and Laforest 2016). This may be evidence of governments that have already been successful at reducing poverty trying to squeeze out further reductions at the margins. If this is indeed the case, the evidence suggests that at least in the short and medium term these efforts have generally not worked. 
Of course, we can also consider the timing of first action plans in a less favourable light. Until relatively recently low-income estimates have taken three or more years to make their way out of Statistics Canada. As a result, expert and public conversations about poverty generally tend to address the recent past rather than present. In some instances, new governments could be enacting action plans in order to take credit for the achievements of past governments.

This conclusion is not really supported by the evidence given that the majority of action plans were released after governments had been in power for at least five years. Even in Quebec - the only province in which we see a government enacting an action plan in its first year of government - the initial commitment to creating a PRS arose after the Parti Quebecois had been in power for as much time. This tendency for action plans to arise relatively late in government terms appears to extend to later action plans.

Still, poverty reduction may have had relatively little to do with actions taken by any plans enacted by provincial governments. It is evident in the final panel in Figure 4 that there have been nationwide trends in changes in poverty levels. Following peak provincial increases in poverty in the 1990s, levels tended to decrease in the 2000s. Provincial poverty developments may in large part be determined by national or even global level forces.

\section{Future directions}

Given the exploratory purpose of this study it is valuable to now identify directions for future study. First and foremost, there has been considerable diversity in the unfolding and substance of PRS among the Canadian provinces. Crucially, some aspects of PRS may be more likely to reduce poverty than others. Work needs to be done, along the lines of that already started by Notten and Laforest (2016), to develop more in-depth frameworks for assessing differences among action plans and their expected impact.

Second, the conclusions formulated in this study pertain primarily to first action plans and they may not extend to subsequent action plans. At this time, Quebec, Ontario, New Brunswick and Manitoba have passed second action plans, but they are too few and have happened too recently for us to say anything conclusive about them. In the years to come, it will be important to consider whether the nature of initial commitments, legislation and first action plans bear on later plans, and whether PRS can be a driver of deliberative evidence-based policy learning.

Third, this study has focused on poverty outcomes and what they suggest about the motivation for and impact of PRS in Canada. However, I essentially treat the governments that enact them as black boxes. Regardless of whether the effective impact of PRS is to dress up or claim credit for recent poverty reduction successes, this may not necessarily have been the intent of 
government actors. Further research on the thinking of decision makers around PRS could improve our understanding of them.

Fourth, the primary aim of this study is to make a "first past," so to speak, of the impact that PRS have had on poverty levels among the Canadian provinces. As such, I adopt a relatively straightforward descriptive empirical strategy. More in-depth analyses of the impact of PRS in Canada is possible using more advanced regression methods and more complex measures of poverty..

Fifth, even though the aim of PRS is generally stated as reducing poverty in the population at large, there is evidence to suggest that PRS have been successful at reducing poverty among targeted subpopulations, such as families in Quebec (van den Berg et al. 2017). Further research may want to explore how PRS have impacted specific subpopulations and, given that these accomplishments have not reduced overall poverty levels, whether there are poverty reduction tradeoffs around PRS.

Finally, an important technical consideration that could inform future analysis and the assessment of PRS in the long term is whether changes in poverty rates are affected by their levels. That is, do decreases in poverty become more difficult as poverty becomes low? On average, poverty levels in the Canadian provinces have declined since the 1970s. When we compare poverty reduction achievements in the present to the past, do we do so on a level playing field?

\section{Conclusion}

In this paper I present a bird's-eye view of the impact that PRS have had on poverty rates among the Canadian provinces. As opposed to focusing on the content and administration of PRS, I take their stated aim - to reduce poverty - at face value and explore whether their enactment is indeed associated with reductions in poverty. Working with forty years of Statistics Canada data I am able to further situate their impact in historical context.

I find that as a general rule the enactment of PRS through actions plans has not been associated with reductions in poverty rates. While there are provinces whose poverty rates have fallen following the introduction of plans - namely Newfoundland and Labrador, Nova Scotia and Manitoba - there have been just as many that have seen poverty fortunes stall or become worse. The lack of discontinuity in poverty rates about PRS suggests that they tend to have an ongoing rather than immediate impact.

In historical context, most first actions plans have actually tended to follow sustained poverty reductions rather than given rise to them. This suggests that PRS may be being used by 
governments to showcase and claim credit for recent achievements around poverty reduction rather than actually reduce poverty going forward. This finding supports the window dressing hypothesis, however, it also casts it in a somewhat more favourable light: governments are not enacting PRS to dress up failures but to underscore successes.

Still, there are reasons to remain optimistic about the promise of PRS. Notten and Laforest (2016) suggest that their ultimate promise may not lay with their immediate impact on poverty but rather with how they change institutional relationships and norms, and introduce new opportunities for learning in ways that are likely to have a longer terms impacts. These kinds of impacts will be most likely in provinces that have committed to reviewing and updating action plans at regular intervals.

Only time will tell whether Canada's provincial PRS will give rise to the kinds of long-term deliberative evidence-based policy learning described by Sanderson (2009). In global context, poverty reduction remains an important policy objective (Noël 2006). At the very least, in the context of "permanent austerity" (Pierson 1998), Canadian poverty outcomes suggest that PRS may offer a rare opportunity for decision makers to engage in affordable credit claiming (Bonoli 2012).

\section{$\underline{\text { References }}$}

Atkinson, Anthony B., Bea Cantillon, Eric Marlier, and Brian Nolan. 2005. Taking Forward the EU Social Inclusion Process. Luxembourg Presidency of the Council of the European Union.

van den Berg, Axel, Charles Plante, Hicham Raïq, Christine Proulx, and Samuel Faustmann. 2017. Combatting Poverty: Quebec's Pursuit of a Distinctive Welfare State. Toronto: University of Toronto Press.

Bernard, Paul and Sebastien Saint-Arnaud. 2004. More of the Same? The Position of the Four Largest Canadian Provinces in the World of Welfare Regimes. Ottawa, ON: Canadian Policy Research Networks Inc. (CPRN).

Bonoli, Giuliano. 2012. "Blame Avoidance and Credit Claiming Revisited." Pp. 93-110 in The Politics of the New Welfare State, edited by G. Bonoli and D. Natali. Oxford: Oxford University Press.

Brady, David. 2003. "Rethinking the Sociological Measurement of Poverty." Social Forces; a Scientific Medium of Social Study and Interpretation 81:715-51.

CBC News. 2016. "Saskatchewan's Poverty Reduction Strategy Released.” CBC News, February 24.

CEPE. 2009. Taking the Measure of Poverty: Proposed Indicators of Poverty, Inequality and Social Exclusion to Measure Progress in Quebec. Quebec: Centre d'étude sur la pauvreté et l'exclusion sociale.

Collin, Chantal. 2007. Poverty Reduction Strategies in the United Kingdom and Ireland. Library of 
Parliament.

Ferrera, Maurizio, Manos Matsaganis, and Stefano Sacchi. 2002. "Open Coordination against Poverty: The New EU ‘social Inclusion Process’.” Journal of European Social Policy 12(3):227-39.

Foster, James, Joel Greer, and Erik Thorbecke. 1984. "A Class of Decomposable Poverty Measures." Econometrica: Journal of the Econometric Society 52(3):761-66.

Fraser, D. C. 2016. “Community Not Happy with Province's Poverty Reduction Strategy.” Regina Leader-Post, February 25.

GoNL. 2006. Reducing Poverty: An Action Plan for Newfoundland and Labrador. Government of Newfoundland and Labrador.

Greason, Vincent. 2012. "Poverty as a Human Rights Violation* (*Except in Governmental Anti-Poverty Strategies)." in Table ronde des OVEP de l'Outaouais.

Holden, Bill and Nazeem Muhajarine. 2015. "Quality of Life Research in Saskatoon, Canada: Fifteen Years of Co-Creating Knowledge and Action in the Community." Engaged Scholar Journal: Community-Engaged Research, Teaching, and Learning 1(2).

Hunter, Garson and Dionne Miazdyck. 2006. "Current Issues Surrounding Poverty and Welfare Programming in Canada.” Pp. 383-418 in Social Fabric Or Patchwork Quilt: The Development of Social Policy in Canada, edited by R. Blake and J. Keshen. Peterborough, Ontario: Broadview Press.

Imbeau, Louis M. et al. 2000. "Comparative Provincial Policy Analysis: A Research Agenda." Canadian Journal of Political Science. Revue Canadienne de Science Politique 4:779-804.

Levinsohn, Jim. 2003. The World Bank's Poverty Reduction Strategy Paper Approach: Good Marketing Or Good Policy? United Nations.

MacInnes, Tom, Sabrina Bushe, Peter Kelly, and Fiona McHardy. 2014. International and Historical Anti-Poverty Strategies: Evidence and Policy Review. New Policy Institute \& Poverty Alliance.

Murphy, Brian, Xuelin Zhang, and Claude Dion. 2010. Revising Statistics Canada's Low Income Measure (LIM). Statistics Canada, Income Statistics Division.

Noël, Alain. 2006. “The New Global Politics of Poverty.” Global Social Policy 6(3):304-33.

Notten, Geranda and Rachel Laforest. 2016. Poverty Reduction Strategies in Canada: A New Way to Tackle an Old Problem? Maastricht Economic and Social Research Institute on Innovation and Technology (UNU-MERIT).

Osberg, Lars and Kuan Xu. 2008. "How Should We Measure Poverty in a Changing World? Methodological Issues and Chinese Case Study." Review of Development Economics 12(2):419-41.

Osberg, Lars and Kuan Xu. 2000. "International Comparisons of Poverty Intensity: Index Decomposition and Bootstrap Inference.” The Journal of Human Resources 35(1):51-81.

Pierson, Paul. 1998. “Irresistible Forces, Immovable Objects: Post-Industrial Welfare States Confront 
Permanent Austerity.” Journal of European Public Policy 5(4):539-60.

Sanderson, Ian. 2009. "Intelligent Policy Making for a Complex World: Pragmatism, Evidence and Learning.” Political Studies 57(4):699-719.

Statistics Canada. 2015. Revisions to 2006 to 2011 Income Data. Statistics Canada.

Weaver, Kent R. 1986. “The Politics of Blame Avoidance.” Journal of Public Policy 6(4):371-98. 


\section{Appendix: Provincial PRS Action Plans}

\section{Newfoundland and Labrador}

Newfoundland and Labrador enacted its first PRS action plan in June 2006 and has not enacted another since. The Progressive Conservative government of the day made its commitment to enact such a plan in its Speech from the Throne the previous year.

GoNL. 2006. Reducing Poverty: An Action Plan for Newfoundland and Labrador. Government of Newfoundland and Labrador.

\section{Prince Edward Island}

The Liberal government of Prince Edward Island delivered the province's first PRS action plan in May 2012. The plan fullfilled a commitment made in its Speech from the Throne in 2010.

GoPE. 2012. Prince Edward Island Social Action Plan to Reduce Poverty. Government of Prince Edward Island.

\section{Nova Scotia}

Near the end of their decade long term in office, the Progressive Conservative led Government of Nova Scotia released the province's first and only PRS action plan to date. This followed the government's commitment to establish this plan with Bill 94 - An Act to Establish a Poverty Reduction Working Group.

GoNS. 2009. Preventing Poverty. Promoting Prosperity: Nova Scotia's Poverty Reduction Strategy. Government of Nova Scotia.

\section{New Brunswick}

The Liberal Government of New Brunswick launched that province's first PRS action plan in 2009 following an initial commitment in 2008. This enactment was followed by legislation in the form of Bill 39 - Economic and Social Inclusion Act. In 2014, the province launched its second action plan under a Progressive Conservative government.

GoNB. 2009. Overcoming Poverty Together: The New Brunswick Economic and Social Inclusion Plan. Government of New Brunswick.

GoNB. 2014. Overcoming Poverty Together: The New Brunswick Economic and Social Inclusion Plan 2014-2019. Government of New Brunswick.

\section{Quebec}

Quebec introduced its first PRS action plan in April 2004 under a Liberal government. This followed an initial commitment made by the previous Parti Quebecois government in the form of 
a motion to the Assemblée Nationale in 2000 and legislation-L-7 - Act to Combat Poverty and Social Exclusion - it passed in 2002. The same Liberal government that enacted the province's first action plans enacted its second in 2010 and a subsequent Liberal government its third in 2017.

GoQC. 2004. Reconciling Freedom and Social Justice: A Challenge for the Future: Government Action Plan to Combat Poverty and Social Exclusion. Government of Quebec.

GoQC. 2010. Québec's Combat Against Poverty 2010-2015: Government Action Plan for Solidarity and Social Inclusion. Government of Quebec.

GoQC. 2017. Plan D'action Gouvernemental Pour L'inclusion économique et La Participation Sociale 2017-2023: Un Revenu de Base Pour Une Société plus Juste. Government of Quebec.

\section{Ontario}

Ontario has launched two action plans under on continuous Liberal government, first in 2008 and again in 2014. Unlike in many other provinces, the action plan was not preceded by a public commitment to devise a plan. In 2009, the province adopted poverty reduction legislation: Bill 152 - Poverty Reduction Act.

GoON. 2008. Breaking the Cycle: Ontario's Poverty Reduction Strategy. Government of Ontario.

GoON. 2014. Realizing Our Potential: Ontario's Poverty Reduction Strategy 2014-2019. Government of Ontario.

\section{Manitoba}

Manitoba enacted its first PRS action plan in 2009 under and NDP government. As in Ontario's case, the plan came without a prior commitment. Following the passing of The Poverty Reduction Strategy Act in 2011, the same government released the province's second action plan in 2012.

GoMB. 2009. All Aboard: Manitoba's Poverty Reduction Strategy. Government of Manitoba.

GoMB. 2012. All Aboard: Manitoba's Poverty Reduction Strategy. Government of Manitoba.

\section{Saskatchewan}

In the 2014 Speech from the Throne, the the right of centre Saskatchewan Party led Government of Saskatchewan committed to creating a PRS. This plan was introduced by the same government in 2016. 
GoSK. 2016. Taking Action on Poverty: The Saskatchewan Poverty Reduction Strategy. Government of Saskatchewan.

\section{Alberta}

In a 2012 pre-election promise Alison Redford committed Alberta to creating a PRS action plan under her Progressive Conservative government. Despite completing widespread consultations, more than five years on and a change in government, this plan has yet to materialize.

\section{British Columbia}

In 2017, the latest NDP led British Columbia government committed to develop its first PRS. This was the final province to make this commitment. According to news reports, an action plan and legislation are expected in 2018. 


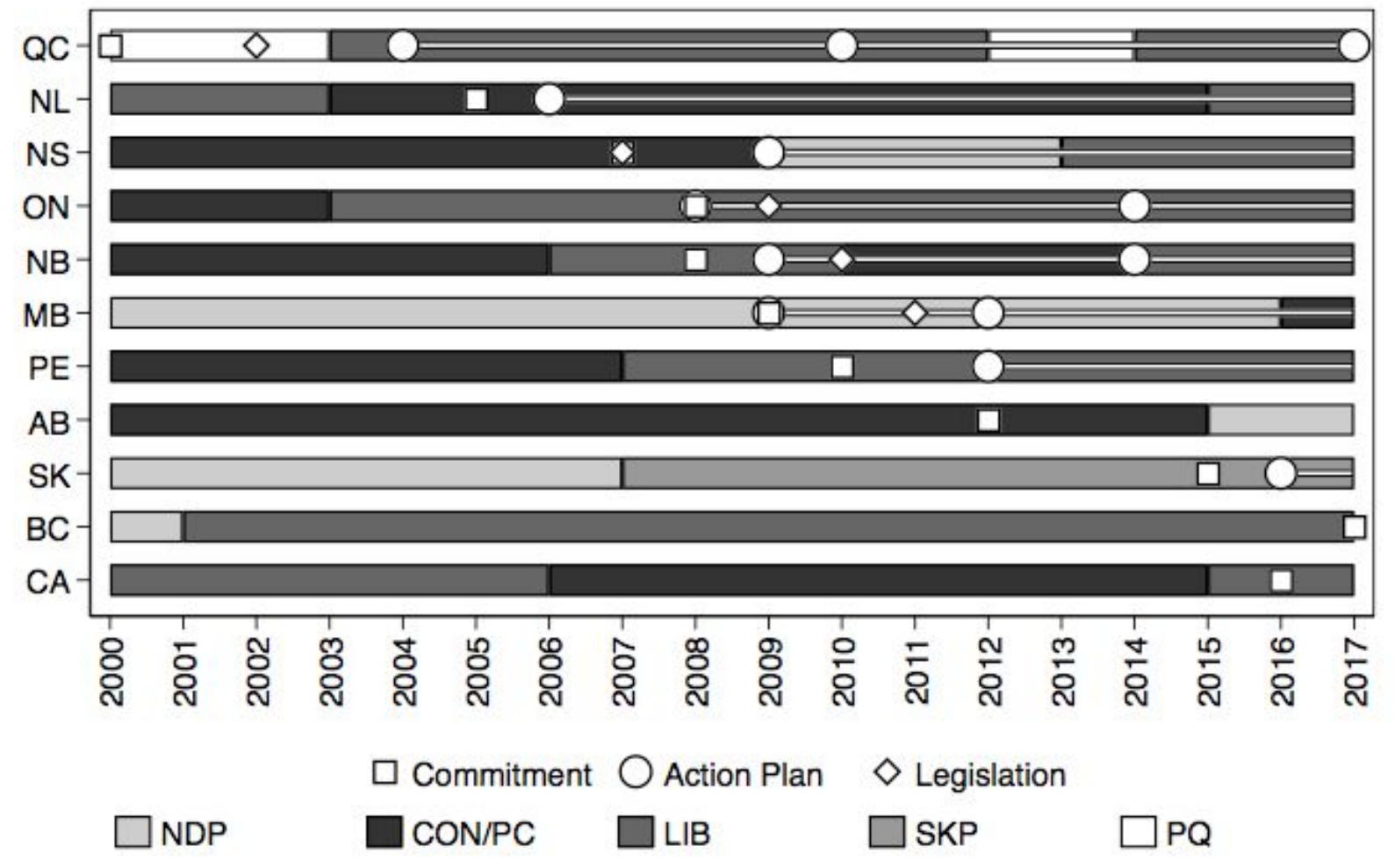

Figure 1. Timing of key political and poverty reduction strategy events for each Canadian province, $2000-2017$ 

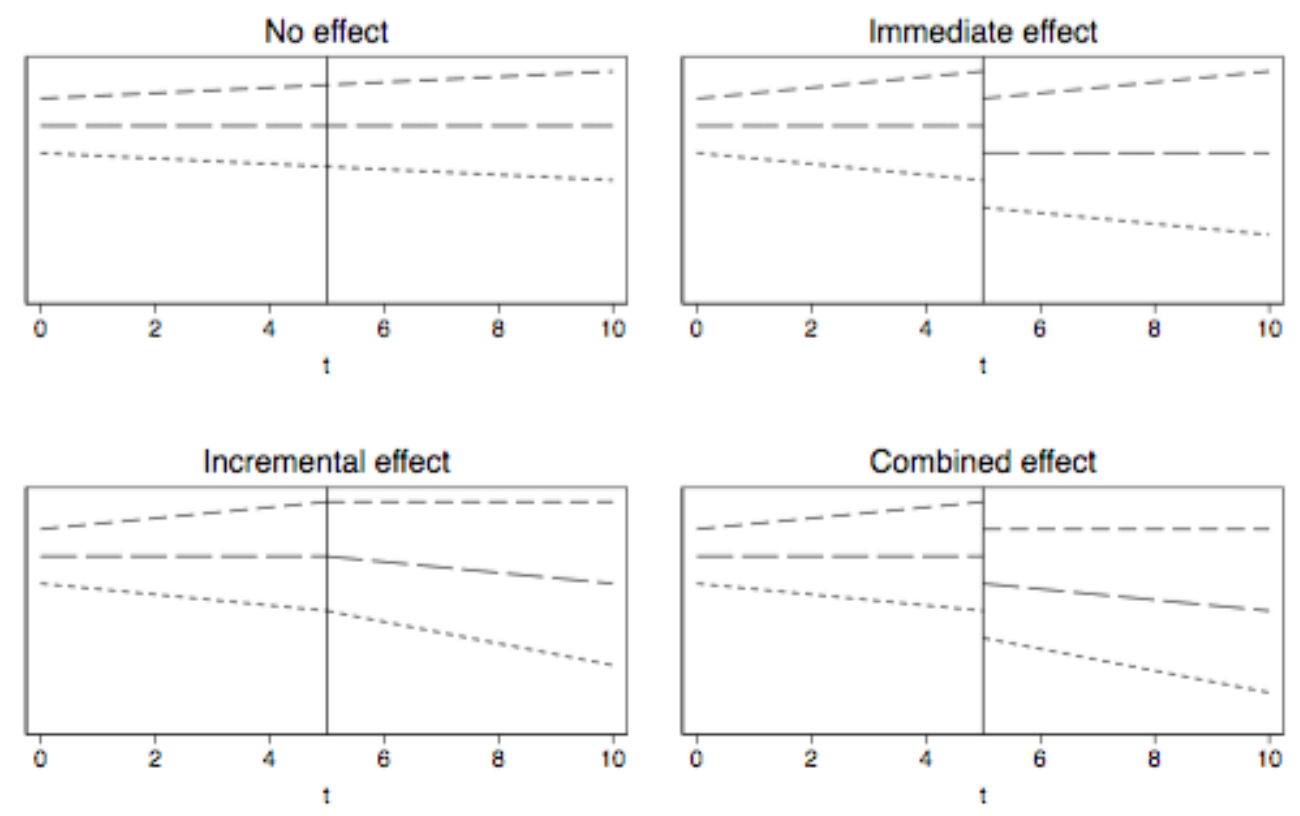

Figure 2. Different hypothetical effects successful poverty reduction strategy action plans should have on different poverty rate trajectories (action plan indicated by solid vertical line) 


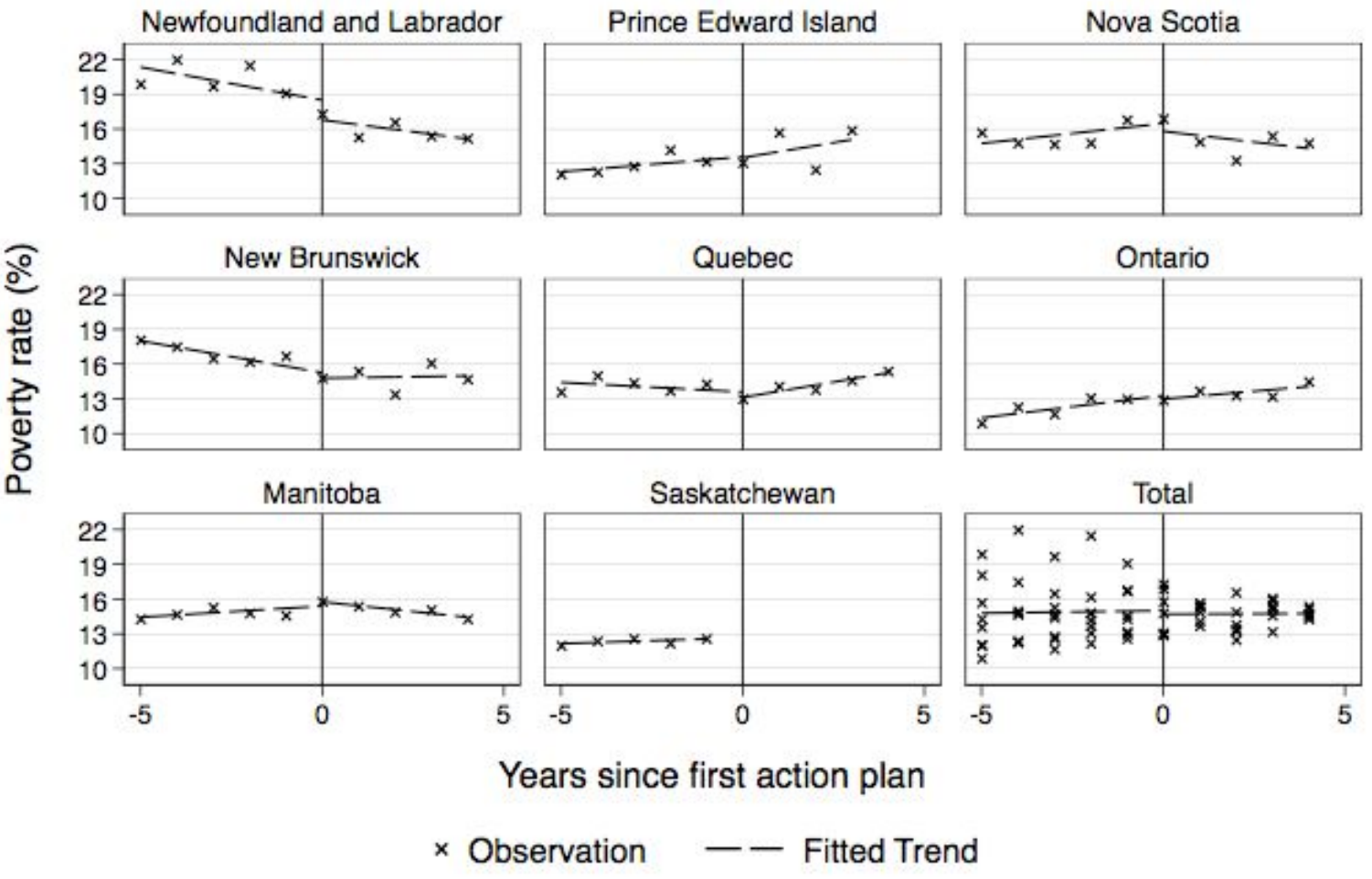

Figure 3. Before and after poverty trajectories among PRS action plan adopting Canadian provinces (action plan indicated by solid vertical line) (Source: SLID \& CIS) 


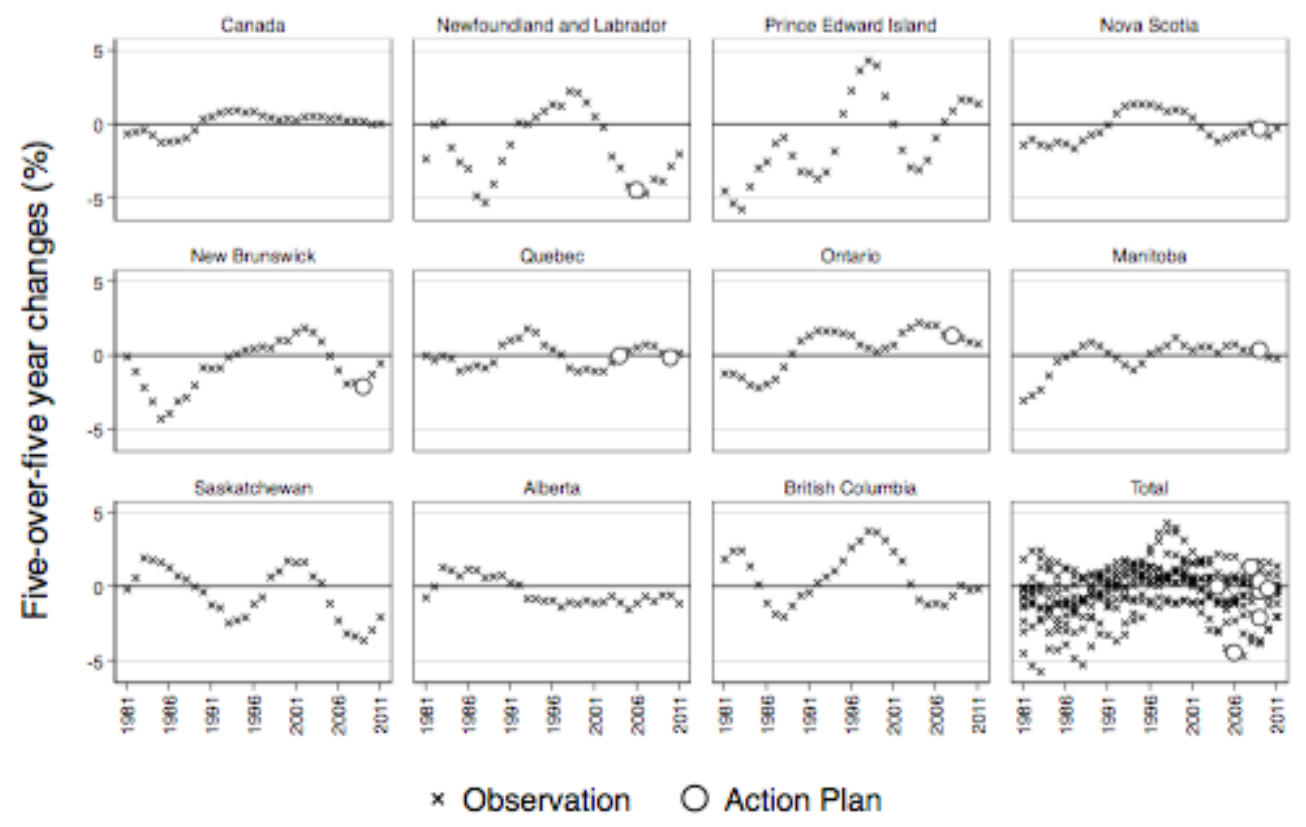

Figure 4. Five-over-five year average changes in poverty rate percentages among the Canadian provinces, 1980-2010 (Source: SCF, SLID \& CIS) 
Table 1. Ten year average poverty rates, for Canada and each province

\begin{tabular}{|c|c|c|c|c|c|c|c|c|}
\hline & \multicolumn{2}{|c|}{$1976-1985$} & \multicolumn{2}{|c|}{$1986-1995$} & \multicolumn{2}{|c|}{$1996-2005$} & \multicolumn{2}{|c|}{$2006-2015$} \\
\hline & Mean & $\mathrm{SE}$ & Mean & SE & Mean & $\mathrm{SE}$ & Mean & SE \\
\hline Newfoundland and Labrador & $24.0 \%$ & 0.002 & $19.2 \%$ & 0.002 & $20.2 \%$ & 0.002 & $15.0 \%$ & 0.003 \\
\hline Prince Edward Island & $19.2 \%$ & 0.005 & $12.8 \%$ & 0.002 & $13.6 \%$ & 0.003 & $13.4 \%$ & 0.003 \\
\hline Nova Scotia & $16.5 \%$ & 0.002 & $14.5 \%$ & 0.001 & $16.1 \%$ & 0.002 & $15.5 \%$ & 0.002 \\
\hline New Brunswick & $19.6 \%$ & 0.002 & $15.2 \%$ & 0.001 & $16.1 \%$ & 0.002 & $15.7 \%$ & 0.002 \\
\hline Quebec & $14.3 \%$ & 0.001 & $14.0 \%$ & 0.001 & $14.4 \%$ & 0.001 & $14.6 \%$ & 0.002 \\
\hline Ontario & $10.2 \%$ & 0.001 & $8.4 \%$ & 0.001 & $10.8 \%$ & 0.001 & $13.6 \%$ & 0.001 \\
\hline Manitoba & $15.3 \%$ & 0.002 & $13.8 \%$ & 0.001 & $14.2 \%$ & 0.002 & $15.1 \%$ & 0.002 \\
\hline Saskatchewan & $16.2 \%$ & 0.002 & $16.8 \%$ & 0.001 & $15.8 \%$ & 0.002 & $13.3 \%$ & 0.002 \\
\hline Alberta & $10.6 \%$ & 0.001 & $11.6 \%$ & 0.001 & $10.2 \%$ & 0.001 & $8.0 \%$ & 0.001 \\
\hline British Columbia & $11.3 \%$ & 0.001 & $10.9 \%$ & 0.001 & $14.6 \%$ & 0.002 & $14.6 \%$ & 0.002 \\
\hline Canada & $12.8 \%$ & 0.000 & $11.6 \%$ & 0.000 & $12.9 \%$ & 0.001 & $13.5 \%$ & 0.001 \\
\hline
\end{tabular}


Table 2. Average poverty rates five years before and after actions plans, including year of enactment

\begin{tabular}{|c|c|c|c|c|c|c|c|c|c|c|}
\hline & \multicolumn{5}{|c|}{ First poverty reduction strategy } & \multicolumn{5}{|c|}{ Second poverty reduction strategy } \\
\hline & \multicolumn{2}{|c|}{ Before } & \multicolumn{2}{|c|}{ After } & \multirow[t]{2}{*}{ Difference } & \multicolumn{2}{|c|}{ Before } & \multicolumn{2}{|c|}{ After } & \multirow[t]{2}{*}{ Difference } \\
\hline & Mean & SE & Mean & SE & & Mean & SE & Mean & SE & \\
\hline Newfoundland and Labrador & $19.2 \%$ & 0.003 & $15.0 \%$ & 0.003 & $-4.20 * * *$ & & & & & \\
\hline Prince Edward Island & $11.6 \%$ & 0.003 & $13.5 \%$ & 0.004 & $1.88 * * *$ & & & & & \\
\hline Nova Scotia & $15.0 \%$ & 0.002 & $14.4 \%$ & 0.003 & $-0.66+$ & & & & & \\
\hline New Brunswick & $16.2 \%$ & 0.003 & $13.4 \%$ & 0.003 & $-2.74 * * *$ & & & & & \\
\hline Quebec & $14.2 \%$ & 0.001 & $14.2 \%$ & 0.001 & -0.02 & $12.7 \%$ & 0.001 & $12.7 \%$ & 0.001 & 0.00 \\
\hline Ontario & $9.0 \%$ & 0.001 & $9.9 \%$ & 0.001 & $0.94 * * *$ & $10.2 \%$ & 0.001 & $11.9 \%$ & 0.002 & $0.02 * * *$ \\
\hline Manitoba & $13.3 \%$ & 0.002 & $13.2 \%$ & 0.002 & -0.12 & $11.9 \%$ & 0.002 & $15.5 \%$ & 0.002 & $0.04 * * *$ \\
\hline
\end{tabular}

